\title{
A DEGRADAÇÃO E FRAGILIDADE DOS SOLOS NO SUDOESTE DE GOIÁS: O CASO DA BACIA HIDROGRÁFICA DO RIBEIRÃO DA PICADA
}

THE DEGRADATION AND FRAGILITY OF SOILS IN SOUTHWESTERN GOIAS: THE WATERSHED CASE OF RIBEIRAO DA PICADA

\section{LA DEGRADACÍON Y FRAGILIDAD DE SUELOS EN EL SUROESTE DE GOIÁS: EL CASO DE LA CUENCA HIDROGRÁFICA DEL RIBEIRÃO DA PICADA}

Régia Estevam-Alves ${ }^{1}$ Universidade Nova de Lisboa, Portugal Luzia Francisca-de-Souza ${ }^{2}$ Valéria Maria-de-Souza ${ }^{3}$

Thales Augusto Ferreira-Queiroz ${ }^{4}$ Jéssica Vieira-Lima ${ }^{5}$ Universidade Federal de Goiás, Brasil

1 Régia Estevam-Alves, Doutoranda em Geografia na Universidade Nova de Lisboa/Portugal. Email: regiaestevam@gmail.com

2 Luzia Francisca de Souza, Professora no Instituto de Ciências Biológicas da UFG/Regional Jataí/Brasil. Email: lufs_go@yahoo.com.br

3 Valéria Maria de Souza, Discente do curso de Engenharia Florestal da UFG/Regional Jataí/Brasil. Email: valeriamariadesouza@hotmail.com

4 Thales Augusto Ferreira-Queiroz, Discente do curso de Engenharia Florestal da UFG/Regional, Jataí/ Brasil. Email: tafq@hotmail.com

5 Jéssica Vieira-Lima, Discente do curso de Engenharia Florestal da UFG/Regional Jataí/Brasil. Email: jessica23lima@yahoo.com.br

Fecha de recepción: 23 de noviembre del 2015

Fecha de aceptación: 24 de noviembre del 2015 
Régia Estevam-Alves, Luzia Francisca-de-Souza, Valéria Maria-de-Souza, Thales Augusto Ferreira-Queiroz, Jéssica Vieira-Lima. The degradation and fragility of soils in southwestern goias: the watershed case of ribeirao da picada

\title{
RESUMO
}

Este trabalho apresenta uma reflexão sobre a degradação dos solos do ponto de vista da fragilidade ambiental, tendo como área de estudo a Bacia Hidrográfica do Ribeirão da Picada/GO. Para isso elaborou-se a fragilidade potencial e emergente dessa bacia hidrográfica utilizando informações e dados sobre o clima, os solos, a declividade, erosividade e o uso da terra. Além disso, fez-se uma revisão bibliográfica acerca da questão da degradação dos solos e de metodologias utilizadas para elaboração de fragilidade ambiental. Os resultados mostraram que a elaboração da fragilidade ambiental possibilita conhecer as características do ambiente da bacia hidrográfica, permitindo identificar quais as áreas mais propensas à degradação.

Palavras-chave: Ecossistemas; Degradação dos solos; medidas mitigatórias.

\begin{abstract}
This paper presents a reflection on the degradation of soils from the environmental fragility point of view, having as area of study the watershed of Ribeirao da Picada/GO. For this purpose, the potential and emerging fragility of that watershed has been established by using information and data on climate, soils, slope, rainfall erosivity and land use. In addition, there was a literature review on the issue of land degradation and methodologies used to establish the environmental fragility. The results showed us that the preparation of the environmental fragility makes it possible to know the characteristics of the watershed environment, allowing the identification of areas that are more prone to degradation.
\end{abstract}

Keywords: Ecosystems; Land degradation; mitigation measures.

\section{RESUMEN}

Este artículo presenta una reflexión sobre la degradación del punto de vista de la fragilidad ambiental del suelo, presentando como área de estudio la cuenca hidrográfica del Ribeirão da Picada/GO. Para eso, se ha elaborado la fragilidad potencial y emergente de esta cuenca utilizando información y datos sobre el clima, el suelo, la declividad, erosividad y el uso de la tierra. Además, fue hecha una revisión de la literatura sobre el tema de la degradación y metodologías de la tierra utilizadas en la preparación de la fragilidad del medio ambiente. Los resultados mostraron que la preparación de la fragilidad ambiental permite conocer las características del entorno de las cuencas hidrográficas, lo que permite identificar los más propensos a las áreas de degradación.

Palabras clave: Ecosistema; Degradación del suelo; Medidas de Mitigación.

\section{Introdução}

Atualmente a questão da degradação dos solos tem sido motivo de preocupação por parte da sociedade em geral. $\mathrm{O}$ aumento da população mundial juntamente com o consumismo tem impulsionado uma maior exploração dos recursos naturais, para atender essas demandas. É sabido que desde os tempos mais remotos o ser humano explora a natureza para a sua sobrevivência, no entanto, nos últimos anos tal exploração vem ocorrendo de maneira intensa e irresponsável, sem a consciência de que alguns recursos naturais são finitos ou de difícil recuperação como, por exemplo, o 
solo e a água. E mesmo quando um único recurso natural é degradado, isso pode resultar no desequilíbrio de todo o ecossistema.

Um exemplo de como os ecossistemas vem sendo degradados pode ser observado nas atividades de agricultura e pecuária, onde a produção em larga escala tem causado a redução das áreas de vegetação nativa, sobretudo nas margens dos rios, assoreando os rios e desenvolvendo processos erosivos.

De acordo com dados da FAO (Organização das Nações Unidas para Alimentação e a Agricultura), publicados no ano de 2011, de todo os solos do planeta, 25\% estão degradados. Atualmente, cerca de 1,6 milhões de hectares dos melhores e mais produtivos solos do mundo são utilizados para o cultivo. Convém ressaltar que a degradação dos solos faz com que todos os anos sejam perdidas toneladas da camada agricultável do solo através da erosão, inviabilizando atividades agrícolas. Tal fato deve-se à ausência de cobertura vegetal que deixa o solo desprotegido, impulsionando os processos erosivos, seja por ação eólica ou hídrica.

A degradação dos solos causa prejuízos financeiros e ambientais no sentido de tornar as áreas incapazes de sustentar a vida vegetal, colocando em risco a segurança alimentar e a capacidade de sustentar o bioma natural, pois reduz drasticamente as áreas agricultáveis e a sua capacidade de regeneração natural (UNCCD, 1994). Em consequência, aumentam os custos com a produção agrícola, potencializando o uso de insumos agrícolas que colocam em risco a saúde humana e o equilíbrio de ecossistemas, além do aumento dos preços dos alimentos.

Assim, o problema da degradação e fragilidade do solo vem demandando tanto por parte da ciência quanto da sociedade civil e política, providências urgentes que envolvam estudos de impactos ambientais, que preconizem a recuperação, manejo e conservação dos ecossistemas, em especial dos solos que são a base para a produção vegetal e da cadeia alimentar.

Neste sentido, a realização e divulgação de estudos ambientais que contemplem uma análise a respeito do potencial da fragilidade dos recursos naturais são muito importantes para alertar a população local da real situação da degradação dos ecossistemas. Isso pode servir de estímulo para a adoção de políticas ambientais com medidas mitigadoras.

Este trabalho tem por objetivo apresentar a questão da degradação dos solos a partir da fragilidade ambiental da bacia hidrográfica do 
Régia Estevam-Alves, Luzia Francisca-de-Souza, Valéria Maria-de-Souza, Thales Augusto Ferreira-Queiroz, Jéssica Vieira-Lima. The degradation and fragility of soils in southwestern goias: the watershed case of ribeirao da picada

Ribeirão da Picada em Jataí-Goiás/Brasil, a qual está localizada numa região de intensa atividade de agricultura e pecuária no Sudoeste de Goiás.

\section{Revisão de literatura}

Bacia hidrográfica como unidade espacial

De acordo com Christofoletti (1999), foi a partir do ano de 1945, com a publicação do trabalho do engenheiro hidráulico Robert E. Horton, que os estudos em bacias hidrográficas passaram a representar considerável importância na Ciência. Robert E. Horton estabeleceu as leis do desenvolvimento dos rios e de suas bacias, tal estudo serviu de base para uma nova concepção metodológica, a qual posteriormente deu origem a outras pesquisas envolvendo análise em bacia hidrográfica. No Brasil, foram nas décadas de 80 e 90 do Século XX que ocorreram os maiores índices de estudos considerando bacia hidrográfica como unidade fundamental de pesquisa e planejamento (Gonçalves et al., 2009; Moragas, 2005). Isso devido a vários problemas enfrentados na época com relação ao uso desenfreado dos recursos hídricos.

No que concerne ao termo bacia hidrográfica, esta pode ser definida como uma área de superfície terrestre drenada por um rio principal e seus tributários, cuja delimitação é constituída pelos seus divisores de água (Botelho, 1999). Neste sentido, numa concepção semelhante, Tucci e Mendes (2006, p. 20) elucidam:

Para cada seção de um rio existirá uma bacia hidrográfica. Considerando esta seção, a bacia é toda a área que contribui por gravidade para os rios até chegar a seção que define a bacia. Esta área é definida pela topografia da superfície, no entanto, a geologia do subsolo pode fazer com que parte do escoamento que infiltra no solo escoe para fora da área delimitada superficialmente. [...] As características principais da bacia hidrográfica são a área de drenagem, o comprimento do rio principal, declividade do rio e a declividade da bacia.

Do ponto de vista da Geografia, é importante ressaltar que, a realização de pesquisas tendo a bacia hidrográfica como unidade de estudo, constitui-se numa formidável fonte referencial aos estudos ambientais, pois são nestes espaços que se desenvolvem importantes relações entre 
sociedade e natureza (Santos, 2005). Nestas perspectivas, Moragas (2005, p.32) ressalta que:

Numa visão fisiográfica, a bacia hidrográfica pode ser entendida como área drenada por uma rede de canais influenciada por diversas características topográficas, litológicas, tectônicas, de vegetação, dentre outras. Mas a bacia hidrográfica representa um complexo sistema integrado de inter-relações ambientais, sócio-econômicas e políticas.

Isso evidencia que a bacia hidrográfica pode ser entendida como um sistema onde ocorrem diferentes trocas de energia e matéria entre os componentes, dos quais são os recursos naturais e o homem. Logo, em nível de escala a bacia pode ser considerada um geossistema por apresentar os atributos necessários (potencial ecológico, exploração biológica e ação antrópica) para uma análise integral da paisagem. Deste modo, Gonçalves et al. (2009) que realizou estudos sobre a análise da relação pluvial, erosividade, erodibidade e uso do solo nos processos erosivos atuantes na Bacia do Rio Araguaia - GO/MT, também concorda com a análise integrada de bacias hidrográficas em estudos ambientais, afirmando que numa visão sistêmica a relação entre homem e recursos naturais se dá a partir das ações antrópicas, cujas alterações que ocorrem na superfície de uma bacia hidrográfica contribui para configuração da paisagem local.

Todavia, as mudanças no uso da terra podem resultar em inúmeras consequências como: erosões, alteração da forma das vertentes e taludes, assoreamento dos cursos d'água, mudança do nível de base dos cursos d'água, diminuição da qualidade da água, alteração do ritmo e da vazão do curso d'água, dentre outras. Os problemas advindos desta intervenção podem ser maiores se houver demanda de água para atividades econômicas ou abastecimento de assentamentos humanos.

Esse pensamento já havia sido discutido por Ross (1990, p.14), o qual afirma que:

Toda causa tem seu efeito correspondente, todo benefício que o homem extrai da natureza tem certamente também malefícios. Desse modo, parte-se do princípio de que toda ação humana no ambiente natural ou alterado causa algum impacto em diferentes níveis, gerando alterações com graus diversos de agressão, levando às vezes as condições ambientais a processo até mesmo irreversíveis. 
Régia Estevam-Alves, Luzia Francisca-de-Souza, Valéria Maria-de-Souza, Thales Augusto Ferreira-Queiroz, Jéssica Vieira-Lima. The degradation and fragility of soils in southwestern goias: the watershed case of ribeirao da picada

Nessa mesma perspectiva, Christofoletti (1979, p.57) destaca as causas e efeitos que as intervenções humanas têm na dinâmica organizacional de uma dada bacia hidrográfica:

$\mathrm{O}$ equilíbrio de um sistema representa o ajustamento completo das suas variáveis internas às condicionantes externas [...]. Quando as condições externas permanecem imutáveis, o equilíbrio dinâmico pode chegar ao estado que melhor exprima a organização interna em função das referidas características exteriores, chegando a obter a condição estática de máxima entropia. Esse estado constante ou de estabilidade ("steady state") e atingido quando a importação e a exportação de matéria e energia forem equacionadas por meio do ajustamento das formas do próprio sistema, permanecendo constantes enquanto não se alterarem as condições externas [...]. Em uma bacia hidrográfica, as condições climáticas, litológicas, biogeográficas e outras mais, vão condicionar a estruturação de determinada rede de drenagem e de determinadas formas de relevo. Alcançando o estado de estabilidade, a geometria da rede fluvial e a da morfologia encontra-se em perfeito estado de equilíbrio e só sofrerão modificações se porventura houver alterações nas variáveis condicionantes.

Diante disso, devido ao fato da bacia hidrográfica constituir-se em uma unidade ambiental natural de fácil delimitação, bem como a possibilidade de análise integral de seus componentes, a bacia hidrográfica como unidade espacial torna-se um instrumento de grande interesse científico objetivando a realização de diagnósticos, prognósticos e controle de degradações ambientais (Silva, 2008). Contudo, tendo em vista as degradações e conflitos ambientais decorrentes do processo de uso e ocupação presentes numa bacia hidrográfica, prima-se neste trabalho eleger a Bacia Hidrográfica do Ribeirão da Picada como unidade espacial para estudo sobre fragilidade ambiental, uma vez que essa exige uma avaliação integral dos componentes da bacia (solo, vegetação, clima, relevo, etc).

\section{Degradação do solo}

A degradação dos solos tem afetado terras agrícolas tornando-as improdutivas, sendo um dos mais graves problemas ambientais nos últimos anos. Atualmente a erosão acelerada dos solos, tanto hídrica, como eólica, é responsável por 56\% da degradação dos solos no Mundo (Guerra, Silva e Botelho, 2010). 
A falta de um manejo adequado aos solos, como o uso de maquinários pesados na agricultura, o uso de insumo e agrotóxicos, a retirada da vegetação deixando o solo exposto à ação das chuvas, e o pisoteio de animais em pastagem sem rotatividade são exemplos de causas da degradação dos solos (Imeson, 2006).

Do ponto de vista conceitual, a UNCCD - Convenção de Combate à Desertificação das Nações Unidas (1994) definiu degradação do solo como sendo a redução ou perda da produtividade biológica ou econômica, resultantes do uso ou processos que incluam atividades humanas, sendo os processos erosivos uma das principais características desse fenômeno. Para Galindo et al. (2008), a degradação do solo é o processo que reduz a capacidade do solo em produzir bens ou serviços. Conforme esse autor, o solo é considerado degradado se os processos naturais e antropogênicos atuantes diminuírem a quantidade e qualidade da produção de biomassa. A degradação do solo pode ocorrer por meio da salinização, erosão, compactação dentre outros.

Todavia, a UNCCD (1994) utiliza o termo desertificação para a degradação do solo que ocorre em áreas áridas, semiáridas e subúmidas secas, a qual é induzida por vários fatores como as variações climáticas e atividades humanas. De acordo com essa definição as áreas susceptíveis a desertificação no Brasil estão localizadas na Região Nordeste, Norte de Minas Gerais e Espírito Santo. Entretanto, para a FAO (1986), citado por Araújo, Almeida e Guerra (2010), o termo desertificação é somente um aspecto extremo da deterioração disseminada combinada com o clima adverso e da exploração agrícola.

Diante do exposto, o termo degradação do solo é o mais adequado para referir às degradações na Bacia Hidrográfica do Ribeirão da Picada/ $\mathrm{GO}$, a qual é lócus de estudo deste trabalho, cuja localização geográfica e características climáticas não correspondem à classificação da UNCCD (1994) para o uso do termo desertificação.

Do ponto de vista histórico, a preocupação com a degradação do solo não é recente, assim como também os problemas que a sociedade enfrenta com a destruição desse recurso natural. De acordo com Guerra, Silva e Botelho (2010), cerca de cinco mil anos atrás o avanço da agricultura no Sul da Inglaterra causou a degradação dos solos por erosão acelerada. 
Régia Estevam-Alves, Luzia Francisca-de-Souza, Valéria Maria-de-Souza, Thales Augusto Ferreira-Queiroz, Jéssica Vieira-Lima. The degradation and fragility of soils in southwestern goias: the watershed case of ribeirao da picada

Aproximadamente $75 \%$ da profundidade dos solos ingleses foi perdida num período compreendido entre 4000 e 2000 anos atrás.

Neste contexto, no Brasil, após a revolução na agricultura ocorrida no final da década de 70 do Século XX, se ampliaram as áreas exploradas pela agricultura devido ao vasto aparato tecnológico disponibilizado que se estendia desde maquinários até insumos, fertilizantes e pesticidas. Isso possibilitou a exploração agrícola em solos impróprios para alguns tipos de cultivos, resultando, atualmente, em amplas áreas degradadas e, em alguns casos de difícil recuperação dos solos.

Guerra e Jorge (2012) destacam que nas últimas décadas as Nações Unidas vem demonstrando muita preocupação em relação aos solos, principalmente do ponto de vista da segurança alimentar ligada a redução de áreas agrícolas. Segundo este autor, uma das primeiras iniciativas governamentais no sentido de preocupação com a necessidade de se procurar soluções para a degradação dos solos, foi em 1987 quando a Primeira-ministra da Noruega organizou uma comissão com o objetivo de estimular o desenvolvimento da investigação sobre degradação dos solos.

Além da degradação dos solos e outras questões como, por exemplo, a adoção de um desenvolvimento que pudesse satisfazer as necessidades presentes sem comprometer o futuro das próximas gerações em suprir suas necessidades, o movimento daquela época resultou na elaboração de um relatório intitulado "Nosso Futuro Comum". Este relatório contém um mapa das condições dos solos em todo o Planeta, concluindo que os solos estão sendo erodidos, tornando-se estéreis.

Neste contexto, é evidente que a degradação do solo está intimamente associada ao avanço da agricultura. Com a revolução tecnológica na agricultura aumentou-se não apenas a produção, mas também a degradação dos solos que passaram a ser utilizados de forma intensiva.

Quando os solos são cultivados são iniciados e acelerados vários processos de degradação que levam a deterioração dos solos (Guerra, Silva e Botelho, 2010). Seguindo esse raciocínio de que a degradação dos solos esteja relacionada diretamente com a agricultura, Mota e Valladares que desenvolveram um estudo a respeito da vulnerabilidade à degradação dos solos da bacia do rio Acaraú no Brasil afirmam o seguinte: 
Régia Estevam-Alves, Luzia Francisca-de-Souza, Valéria Maria-de-Souza, Thales Augusto Ferreira-Queiroz, Jéssica Vieira-Lima. A degradação e fragilidade dos solos no sudoeste de goiás: o caso da bacia hidrográfica do ribeirão da picada

A ocupação humana em áreas consideradas vulneráveis sob o ponto de vista agrícola tem aumentado o processo de perda do solo, o qual ocorre naturalmente devido à associação do clima com os tipos de litologia, relevo, solo e cobertura vegetal. [...] A falta de planejamento do uso do solo pode levar a processos erosivos em intensidade e velocidade que ultrapassam os limites de tolerância. Tendo em vista que a degradação dos solos afeta a sustentabilidade do agro-ecossistema inteiro. (2011, p. 40).

Tal afirmação mostra que a degradação dos solos não afeta apenas os solos em si, mas outros elementos do ecossistema como água, fauna e flora, sendo de suma importância a realização de um planejamento adequado no processo de uso e ocupação dos solos, principalmente quando se refere à atividades agrícolas. $\mathrm{O}$ Brasil, por exemplo, é um país que possui extensas áreas degradadas e mesmo assim, não há um controle total e adequado no processo de uso e ocupação dos solos para o cultivo agrícola (Guerra, Silva e Botelho, 2010).

Alves (2012), que realizou um estudo sobre a caracterização da paisagem da bacia hidrográfica do Ribeirão da Picada/GO a partir da fragilidade ambiental, identificou várias áreas da bacia como impróprias para cultivo agrícola e atividades de pecuária intensiva. Observando que mesmo com solos impróprios para a agricultura, extensas áreas dessa bacia foram exploradas de forma intensa e sem controle por várias décadas, o que resultou na presença atual de vários estados de degradação dos solos como a presença de ravinas em grandes profundidades, resultantes da ação da erosão.

Do ponto de vista socioeconômico, segundo Guerra e Jorge (2012), as políticas públicas na definição das propriedades rurais e na gestão das bacias hidrográficas possuem um papel muito importante nos incentivos dados aos agricultores no sentido de se praticar um manejo adequado dos solos, que leve a sua conservação. Assim, o conhecimento sobre erosão e conservação dos solos tem aumentado muito rapidamente nas últimas décadas.

No que se refere ao estudo de degradação dos solos, é muito importante o conhecimento sobre os indicadores de qualidade do solo. Conforme Araújo, Goedert e Lacerda (2007), a qualidade do solo pode ser conceituada na capacidade desse recurso natural exercer várias funções dentro dos limites de uso da terra e do ecossistema, para sustentar a produção biológica, manter e melhorar a qualidade ambiental, contribuindo 
Régia Estevam-Alves, Luzia Francisca-de-Souza, Valéria Maria-de-Souza, Thales Augusto Ferreira-Queiroz, Jéssica Vieira-Lima. The degradation and fragility of soils in southwestern goias: the watershed case of ribeirao da picada

para a saúde das plantas, dos animais e dos seres humanos. De acordo com esses autores, a avaliação da qualidade do solo pode ser feita por meio da quantificação das propriedades físicas, químicas e biológicas.

$\mathrm{O}$ estabelecimento dos índices de qualidade do solo por meio da quantificação dos seus atributos físicos, químicos e biológicos permite o monitoramento das possíveis mudanças no estado de qualidade por um período longo, podendo ser realizado numa propriedade agrícola ou em escalas mais abrangentes como, por exemplo, a de uma bacia hidrográfica.

Contudo, o estudo da degradação dos solos, do ponto de vista da Geografia, não perpassa apenas pela avaliação dos solos em si, mas também de outros elementos ecológicos, sociais e econômicos, podendo citar como exemplo o trabalho de Roxo (1993). Em seus estudos, a autora relaciona as ações antrópicas às transformações ao ambiente natural levando em consideração todos os elementos que compõem um ecossistema, além dos antrópicos. Verificando-se que o processo de degradação dos solos está intrinsecamente ligado à ação antrópica devendo ser analisado de uma forma sistémica.

Analisando as bibliografias sobre degradação dos solos, Roxo (1993), Hermuche, Guimarães e Castro (2009), Ruiz e Bermúdez (2009), Ciampalini, Follain e Le Bissonnais (2010), Guerra e Jorge (2012), foi possível perceber que em todas as questões referentes à erosão recebe uma elevada atenção. Para esses autores, a erosão é responsável pela perda dos horizontes produtivos dos solos, pois junto com o escoamento superficial (superficial e sub-superficial) os nutrientes dos solos responsáveis pelo desenvolvimento das plantas são transportados e consequentemente erodidos. Neste sentido, em estudos sobre degradação dos solos, é de grande relevância que se inclua a avaliação dos processos erosivos no sentido de entender a dinâmica do ambiente e o que pode estar causando as perdas de solos.

Fragilidade ambiental como recurso metodológico em estudos sobre degradação do solo

Fragilidade ambiental trata-se de uma metodologia desenvolvida por Ross (1994), Crepani et al. (1996), os quais tiveram como base as concepções de ecodinâmica preconizadas por Tricart (1977), onde o mesmo recomenda que em estudos sobre planejamento ambiental sejam consideradas as potencialidades dos recursos naturais, bem como, as fragilidades dos ambientes naturais face às ações antrópicas. Contudo, Spörl (2007), uma 
das seguidoras da metodologia de Ross (1994), enfatiza que o termo fragilidade ambiental significa a susceptibilidade do ambiente natural em sofrer alterações, cujo processo de avaliação envolve a compreensão qualitativa e quantitativa entre os aspectos físicos, bióticos e socioeconômicos.

Segundo Ross (2006), nesse tipo de estudo é possível entender a dinâmica de funcionamento dos ambientes naturais com ou sem intervenção humana. Visto que, a funcionalidade dos ambientes naturais é modificada através das ações antrópicas que causam alterações na paisagem num ritmo cada vez mais intenso que aquele produzido na natureza. Neste sentido, Spörl (2007) ressalta que qualquer alteração realizada no ambiente natural, mesmo que seja somente em um dos componentes, esta reflete no restante do sistema gerando impactos na natureza. Para Silva $(2008$, p. 6): "tem-se como fragilidade ambiental a identificação de áreas sensíveis a impactos ambientais, assim como uma baixa capacidade de recuperação".

Nestas perspectivas, quando se trata de fragilidade de ambientes, Tricart (1977) classifica como estáveis os ambientes naturais quando estão em equilíbrio, porém, quando estão em desequilíbrio são instáveis. Ross (1994, p. 63) enfatiza que:

A fragilidade dos ambientes naturais face as intervenções humanas é maior ou menor em função de suas características genéticas. A princípio, salvo algumas regiões do planeta, os ambientes naturais mostram-se ou mostravam-se em estado de equilíbrio dinâmico até o momento em que as sociedades humanas passaram progressivamente a intervir cada vez mais intensamente na exploração dos recursos naturais.

Assim, a ideia da possibilidade de um colapso dos recursos naturais vem provocando muitos questionamentos nesse início de Século XXI. Certamente um desses questionamentos é como tornar harmoniosa a relação entre homem e natureza, visto que essa é a base para o desenvolvimento da sociedade humana, na qual isso decorre historicamente dos processos de uso e ocupação de terras (Silva, 2008). Com isso, a compreensão dos processos de uso e ocupação de terras é importante no entendimento da fragilidade dos ecossistemas, pois representam as atividades antrópicas, as quais podem servir de indicadores de pressão sobre os ecossistemas. 
Régia Estevam-Alves, Luzia Francisca-de-Souza, Valéria Maria-de-Souza, Thales Augusto Ferreira-Queiroz, Jéssica Vieira-Lima. The degradation and fragility of soils in southwestern goias: the watershed case of ribeirao da picada

Nestas perspectivas, a fragilidade ambiental se apresenta como uma ferramenta metodológica importante em estudos sobre degradação do solo, pois sua análise permite um estudo de forma ampla e integrada de vários elementos físicos ambientais e também antrópicos.

\section{Metodologia}

Localização e descrição da área de estudo: Bacia Hidrográfica do Ribeirão da Picada/Goiás/Brasil

A Bacia do Ribeirão da Picada, a qual está localizada na zona rural do município de Jataí, no estado de Goiás/Brasil entre as E $=404000 \mathrm{~m}$, N $=428000 \mathrm{~m}$ e $\mathrm{E}=7990000 \mathrm{~m}, \mathrm{~N}=8014000 \mathrm{~m}$, do Sistema de Coordenadas UTM, fuso 22 (Mapa 1), possui aproximadamente 193,1 km² de extensão, e abrange propriedades rurais que desenvolvem atividades agropecuárias, as quais são significativas para a economia do município.

Mapa 1: Localização da Bacia do Ribeirão da Picada no município de Jataí/Brasil.

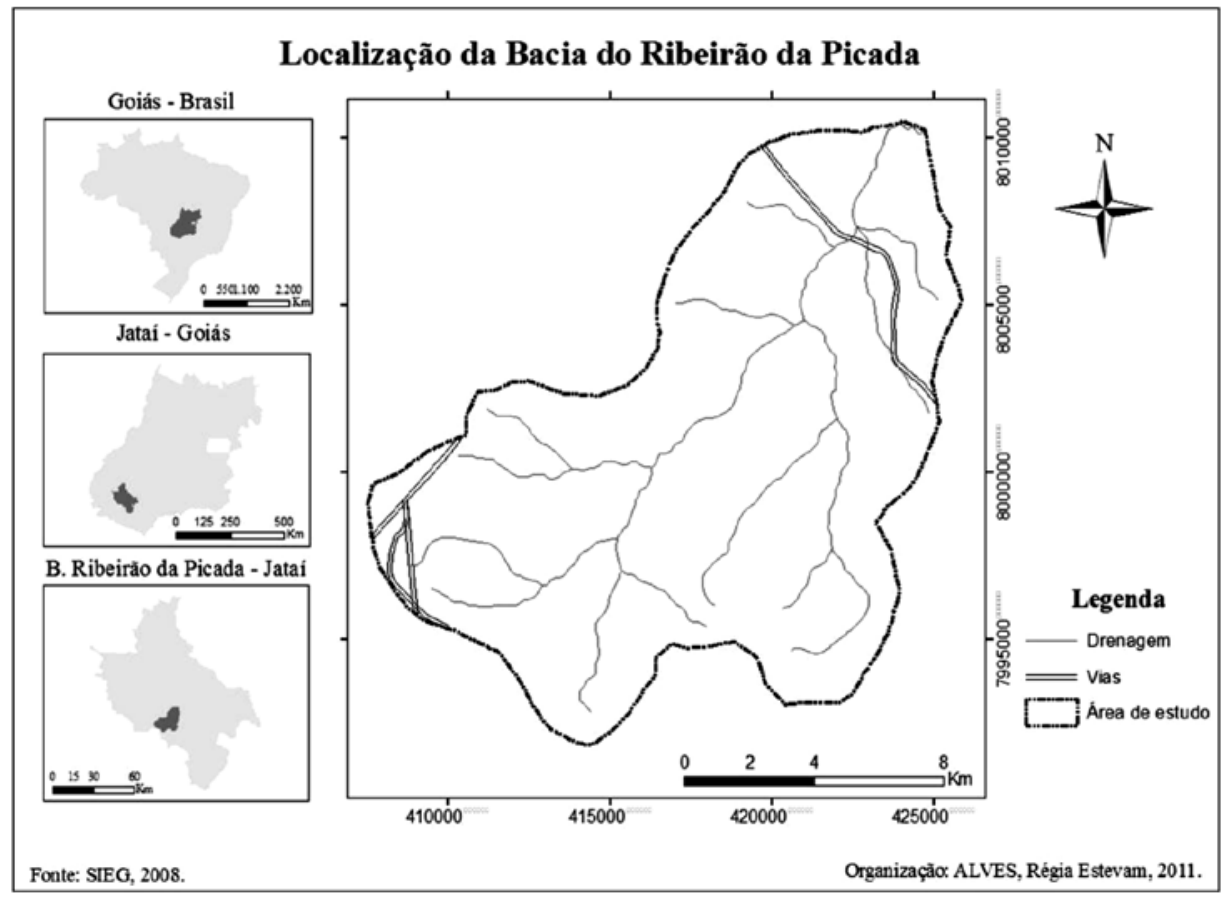


Em termos de características de hidrografia, a Bacia Hidrográfica do Ribeirão da Picada nasce ao sul do município de Jataí, e a drenagem principal, que é abastecida por 12 afluentes, recebe o nome de Ribeirão da Picada (Mapa 1), que deságua no Ribeirão Ariranha, o qual faz parte da bacia hidrográfica do Rio Claro. A bacia está assentada sob arenitos da Formação Vale do Rio do Peixe, em quase toda área da bacia, arenitos da Formação Cachoeirinha de idade Terciária, os quais ocorrem à montante da bacia e sedimentos basálticos da Formação Serra Geral (Radambrasil, 1982; Gonçalves e Schneider, 1970).

Em relação aos tipos de solos na bacia, predomina-se Latossolos Vermelho-amarelos, Latossolos Vermelhos, Argissolos Vermelhos e Neossolos Quartzarênicos (ALVES, 2012). Quanto às características de relevo, a bacia apresenta formas de relevo predominantemente tabulares com dissecações médias, cujas cotas variam entre 550 a $750 \mathrm{~m}$; a jusante da bacia as formas de relevo continuam planas, porém apresentam dissecação fraca a média com cotas entre 800 a $850 \mathrm{~m}$ de altitude (Latrubesse, 2005).

No que se refere à cobertura vegetal nativa na bacia, os remanescentes do Bioma Cerrado, correspondem às áreas florestadas (Matas Seca, Ciliar, de Galeria e Cerradão) e savânica (cerrado), segundo Ribeiro e Valter (1998). O clima é característico de tropical de continentalidade pronunciada, apresentando um longo período chuvoso (outubro a março), ou seja, tropical chuvoso - Aw, opondo-se a outro mais seco (abril a setembro) (Antunes, 2006).

\section{Procedimentos metodológicos}

Este estudo é parte da pesquisa de mestrado da autora, cujo tema foi a caracterização da paisagem a partir da fragilidade ambiental da Bacia Hidrográfica do Ribeirão da Picada no município de Jataí/GO/Brasil. Diante do exposto, o estudo envolveu três etapas para a elaboração das fragilidades potencial e emergente, conforme a figura 1. 
Régia Estevam-Alves, Luzia Francisca-de-Souza, Valéria Maria-de-Souza, Thales Augusto Ferreira-Queiroz, Jéssica Vieira-Lima. The degradation and fragility of soils in southwestern goias: the watershed case of ribeirao da picada

Figura 1: Fluxograma da sequência dos procedimentos.

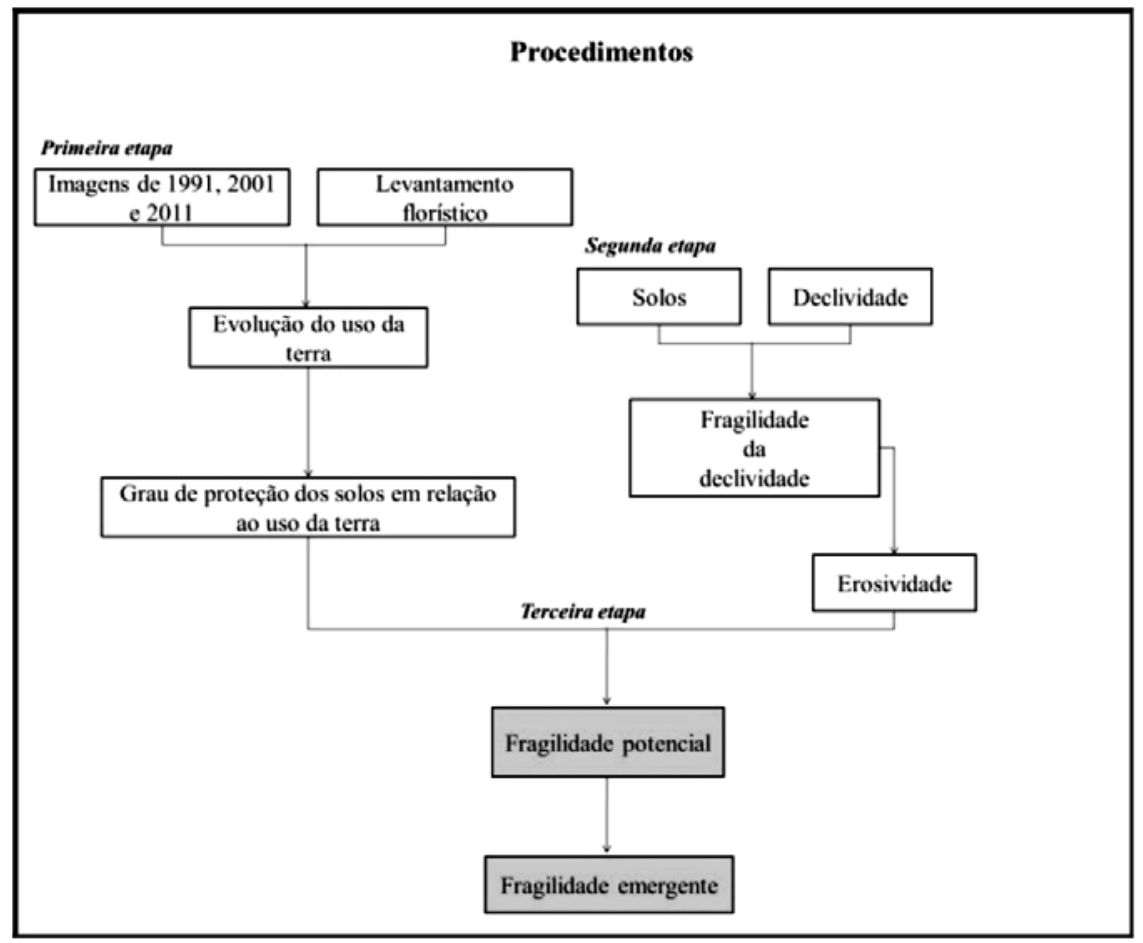

A primeira etapa consistiu no mapeamento da evolução do uso da terra para os anos de 1991, 2001 e 2011, onde foram utilizadas imagens de satélite TM Landsat 5 correspondentes ao quadrante SE22-vd e SE22-yb, obtidas no site do INPE- Instituto Nacional de Pesquisas Espaciais. Também foi realizado um levantamento florístico visando identificar que tipo de vegetação predomina na área de estudo. Além disso, utilizando a base cartográfica do mapeamento uso da terra do ano de 2011 foi elaborado um mapeamento do grau de proteção que cada tipo de cobertura vegetal representa hierarquicamente à cada tipo de solo.

Segunda etapa do trabalho consistiu na elaboração de mapeamentos dos tipos de solos, declividade, fragilidade da declividade e erosividade. Para isso foram utilizados dados do SIEG - Sistema Estadual de Estatísticas de Informações Geográficas e da NASA - National Aeronautics and Space Administration, os quais foram processados nos softwares Spring 5.1.6 e ArcGis 9.3. 
A terceira etapa correspondeu à elaboração do mapeamento das fragilidades potencial e emergente que é o foco de interesse deste trabalho.

\section{Mapeamento da fragilidade potencial}

A fragilidade potencial é caracterizada pelo equilíbrio dinâmico natural entre os elementos do sistema. A fragilidade potencial da Bacia Hidrográfica do Ribeirão da Picada foi determinada a partir do cruzamento das informações sobre declividade, solos e erosividade da bacia.

A elaboração da declividade seguiu a divisão das classes proposta por Ramalho Filho e Beek (1995), onde se adota os seguintes valores de declividade: $0-3 \%$; de $3-8 \%$; de $8-13 \%$; de 13 a $20 \%$ e acima de $20 \%$. Os tipos de solo da área de estudo foram classificados de acordo a EMBRAPA (2006), e os valores de erosividade foram obtidos por intermédio do método adaptado por Bertoni e Lombardi Neto (1999).

Para cada um dos parâmetros (declividade, solos e erosividade) foram atribuídos dígitos representando seis níveis hierárquicos de fragilidade que variam em classes: (1) Muito Forte, (2) Forte, (3), Baixa, (4) Muito baixa ou (6) Nula. Os níveis de fragilidade encontrados para cada um dos parâmetros podem ser verificados no Quadro 1. Posteriormente, a fragilidade potencial foi obtida a partir do cruzamento que sintetizou a combinação dos dígitos dos respectivos níveis de fragilidade da declividade, dos solos e da erosividade.

Quadro 1: Informações dos níveis de fragilidade das variáveis utilizadas para a elaboração do mapa de fragilidade potencial da Bacia Hidrográfica do Ribeirão da Picada/GO/Brasil.

\begin{tabular}{|l|l|l|}
\hline $\begin{array}{c}\text { Classes da fragilidade da } \\
\text { declividade }\end{array}$ & $\begin{array}{c}\text { Classes da fragilidade do } \\
\text { solo }\end{array}$ & $\begin{array}{c}\text { Classes da fragilidade da } \\
\text { erosividade }\end{array}$ \\
\hline (3)-----------Média & $(3)$------------Média & (5)----------Muito forte \\
\cline { 1 - 2 } (4)------------Forte & ( 4)-----------Forte & \\
\hline (5)-----------Muito forte & $(5$ )-----------Muito forte & \\
\hline
\end{tabular}

Adaptado de Ross (1994).

\section{Mapeamento da fragilidade emergente}

As áreas que correspondem à fragilidade emergente são caracterizadas pelas ações antrópicas, as quais causam desequilíbrio na dinâmica organizacional do ambiente. Nessas perspectivas, a fragilidade emergente 
Régia Estevam-Alves, Luzia Francisca-de-Souza, Valéria Maria-de-Souza, Thales Augusto Ferreira-Queiroz, Jéssica Vieira-Lima. The degradation and fragility of soils in southwestern goias: the watershed case of ribeirao da picada

foi determinada a partir do cruzamento das informações da fragilidade potencial com as informações do grau de proteção aos solos em relação ao uso da terra. Para isso, foram combinados os dígitos das informações da fragilidade potencial com todos os dígitos do grau de proteção do uso da terra (quadro 2).

Quadro 2: Informações dos níveis de fragilidade das variáveis utilizadas para a elaboração do mapa de fragilidade emergente da Bacia Hidrográfica do Ribeirão da Picada no município de Jataí/GO/Brasil.

\begin{tabular}{|l|l|}
\hline \multicolumn{1}{|c|}{ Classes de fragilidade potencial } & \multicolumn{1}{c|}{ Classes de grau de proteção aos solos } \\
\hline (4)-----------Forte & $(1)-----------M u i t o$ alta \\
\hline (5)----------Muito forte & $(2)-----------$ Alta \\
\hline & $(3)-----------$ Média \\
\hline & $(4)-----------$ Baixa \\
\hline & $(5)-----------M u i t o$ baixa ou nula \\
\hline
\end{tabular}

* ( ) Dígitos correspondentes a classe hierárquica de fragilidade / Adaptado de Ross (1994).

\section{Resultados}

Os resultados mostraram que o ambiente da Bacia Hidrográfica do Ribeirão da Picada/GO possui naturalmente uma fragilidade elevada para se degradar devido às características naturais dos solos, do relevo, da declividade e da dinâmica das chuvas, os quais podem influenciar ou não no equilíbrio do ambiente da bacia.

Conforme os resultados apresentados (Mapa 2) a fragilidade potencial de maior representatividade na bacia é a classe Forte que abrange cerca de $94,16 \%$ da área total da bacia, onde os solos são representados pelos Latossolos bem drenados, com textura argilosa a média argilosa e com declividade que varia entre 6 a 20\%. Embora nessas áreas da bacia a declividade seja menos acentuada, as características texturais dos Latossolos influenciam nesse resultado, pois em caso de ausência de cobertura vegetal, quanto maior o percentual de areia no solo, maior a propensão à perda de partículas, seja por escoamento superficial causado pela intensidade da chuva, seja por processos eólicos. 
Régia Estevam-Alves, Luzia Francisca-de-Souza, Valéria Maria-de-Souza, Thales Augusto Ferreira-Queiroz, Jéssica Vieira-Lima. A degradação e fragilidade dos solos no sudoeste de goiás: o caso da bacia hidrográfica do ribeirão da picada

Mapa 2: Fragilidade potencial da Bacia Hidrográfica do Ribeirão da Picada no município de Jataí/GO/Brasil, no ano de 2011.

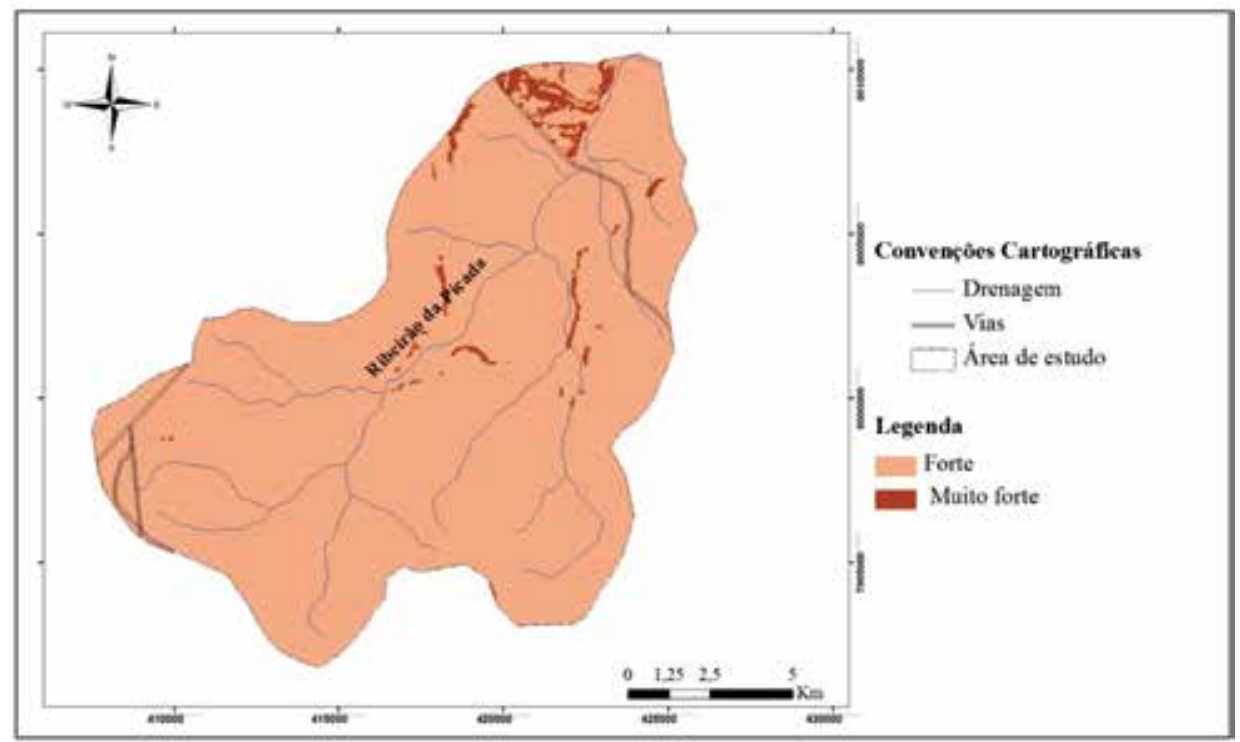

Fonte: SIEG, 2008; ASSIS, Idelina Cabral, 1999; NASA, 2011 - Imagem SRTM 30, maio de 2011. Organização: ALVES, Régia Estevam.

A fragilidade potencial considerada Muito forte ocorre em torno de $5,84 \%$ da bacia, coincidindo com as áreas de declividade mais acentuadas, as quais variam de $20 \%$ à acima de $30 \%$ de declive, abrangendo todas as classes de solos encontrados na bacia (Mapa 2). Entretanto, a fragilidade potencial é mais representativa nas áreas de ocorrência dos Neossolos Quartzarênicos, onde os solos apresentam-se muito degradados apresentando erosões e extensas áreas arenosas com visível redução de cobertura vegetal, como mostra a Foto 1. 
Régia Estevam-Alves, Luzia Francisca-de-Souza, Valéria Maria-de-Souza, Thales Augusto Ferreira-Queiroz, Jéssica Vieira-Lima. The degradation and fragility of soils in southwestern goias: the watershed case of ribeirao da picada

Foto 1: Degradação do solo (Neossolo) com formação de áreas arenosas com reduzida cobertura vegetal na Bacia Hidrográfica do Ribeirão da Picada no município de Jataí/GO/Brasil, no ano de 2011.

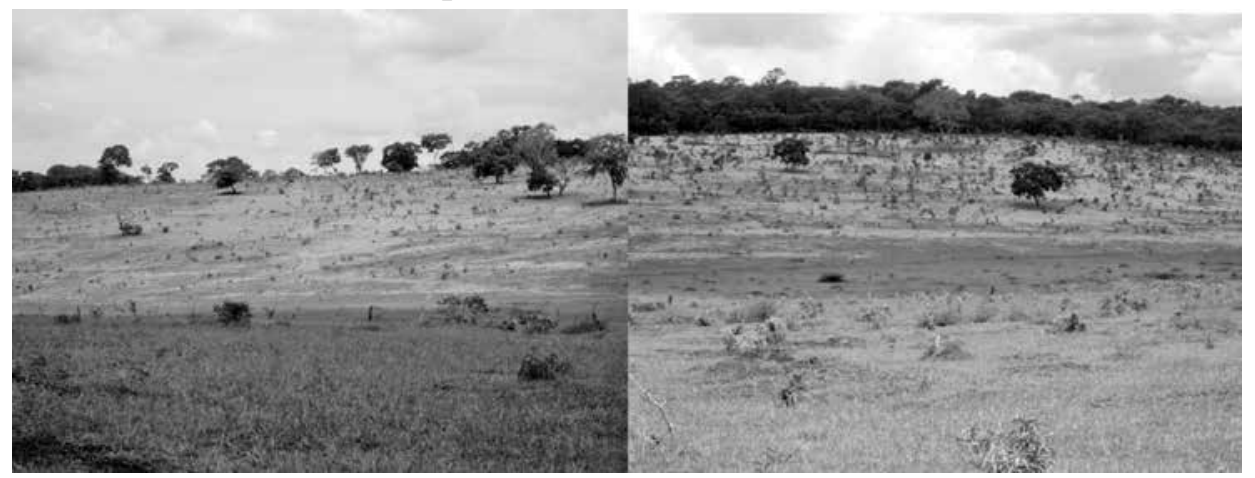

Fonte: Régia Estevam Alves. Trabalhos de campo realizados nos anos de 2010 e 2011.

Além de considerar as características naturais como solo, declividade e erosividade, a fragilidade emergente acrescenta os fatores antrópicos, que se caracteriza pela forma que o homem explora os ambientes naturais. Assim, a fragilidade emergente se configura no equilíbrio ambiental em relação aos ambientes naturais e a exploração destes pelo homem.

O mapeamento da bacia hidrográfica indica que as áreas com fragilidade emergente considerada Muito forte correspondem a 41,81\% (Mapa 3 ). Neste sentido, observou-se que a jusante da bacia hidrográfica a fragilidade emergente é considerada Muito forte, coincidindo com os locais em que apresentam degradações intensas como, processos erosivos em vários estágios do tipo ravinas e voçorocas, além de extensas áreas arenosas sem ou quase sem cobertura vegetal. (Mapa 3 e Foto 1).

Todavia, as áreas com vegetação nativa como Matas, Cerradão e Cerrado, onde a declividade é menos acentuada, indicaram fragilidade emergente considerada Média, correspondendo a $16,21 \%$ do total da bacia. Isso demonstra a relação entre o desmatamento e a mudança negativa nos índices de fragilidade emergente na bacia, ou seja, mesmo sendo uma área com vegetação nativa, essa ainda apresenta uma considerável fragilidade. Evidentemente a presença de matéria orgânica oriunda das folhas que caem das árvores e outros organismos atraídos pela vegetação ajudam a reduzir a fragilidade à degradação nessas áreas da bacia. 
Régia Estevam-Alves, Luzia Francisca-de-Souza, Valéria Maria-de-Souza, Thales Augusto Ferreira-Queiroz, Jéssica Vieira-Lima. A degradação e fragilidade dos solos no sudoeste de goiás: o caso da bacia hidrográfica do ribeirão da picada

Outro fator importante verificado é que embora a pastagem e os cultivos agrícolas sejam um tipo de cobertura vegetal suas características nem sempre oferecerem proteção adequada aos solos. Isso pode ser influenciado pelo tipo de cultura, se a pastagem é intensa e sem rotatividade de pastos. Nestas perspectivas, os resultados mostraram que a fragilidade Forte ocorre em $41,98 \%$ da bacia nas áreas de pastagem e lavouras, como mostra as Fotos $2 \mathrm{a}$ e b, o que alerta para a necessidade de maior responsabilidade no manejo dos solos na Bacia Hidrográfica do Ribeirão da Picada.

Mapa 3: Fragilidade emergente da Bacia Hidrográfica do Ribeirão da Picada no município de Jataí/GO/Brasil, no ano de 2011.

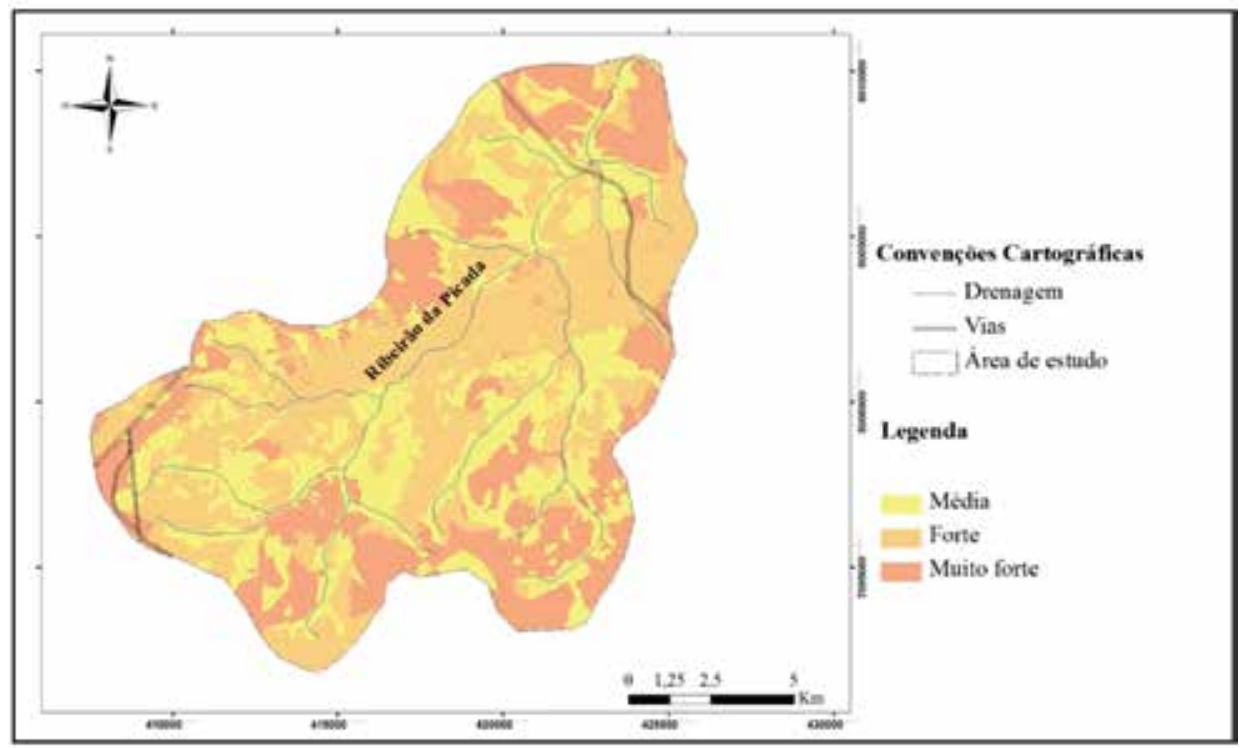

Fonte: INPE, 2011 - Imagem TM Landsat 5 (5R4G3B); SIEG, 2008, NASA, 2011 - Imagem SRTM 30, maio de 2011, ASSIS, Idelina Cabral, 1999.

Organização: ALVES, Régia Estevam. 
Régia Estevam-Alves, Luzia Francisca-de-Souza, Valéria Maria-de-Souza, Thales Augusto Ferreira-Queiroz, Jéssica Vieira-Lima. The degradation and fragility of soils in southwestern goias: the watershed case of ribeirao da picada

Foto 2: A- Degradação dos solos em área de pastagem. B- Degradação dos solos em área de lavoura na Bacia Hidrográfica do Ribeirão da Picada no município de Jataí/GO, no ano de 2011.

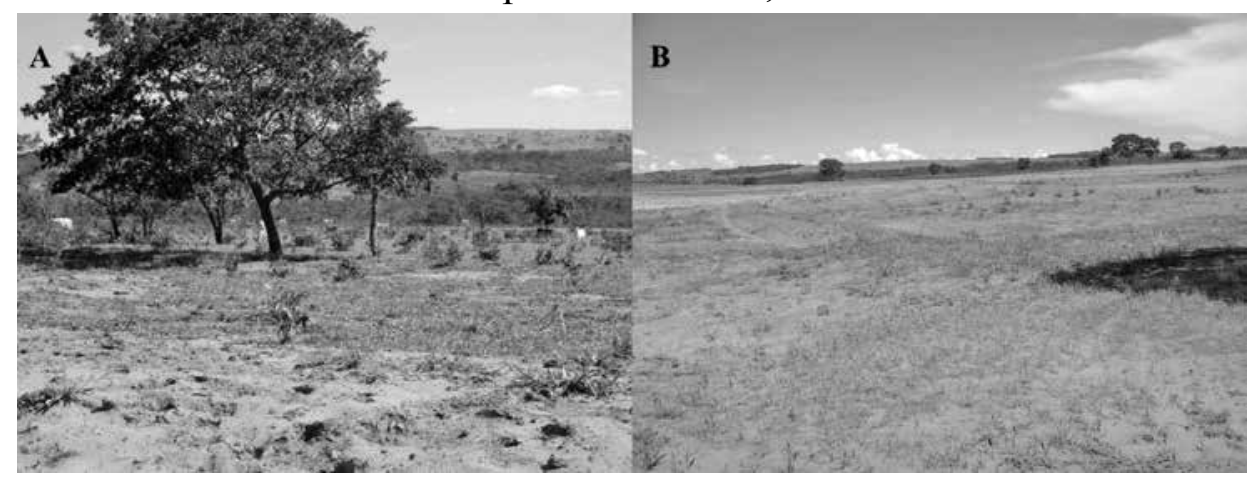

Fonte: Régia Estevam Alves. Trabalhos de campo realizados nos anos de 2010 e 2011.

Historicamente, por várias décadas, a principal atividade econômica nessa bacia hidrográfica foi a pecuária extensiva, sem rotatividade de pastagem em algumas áreas, principalmente à jusante da bacia. No decorrer dos anos, muitas dessas áreas utilizadas como pastagens à montante e no curso médio da bacia foram abandonadas, o que pode ter contribuído para a regeneração da vegetação nativa em alguns locais. No entanto, o mesmo não ocorreu à jusante da bacia, pois as atividades de pecuária extensiva sem rotatividade de pastagem se intensificaram cada vez mais, o que certamente contribuiu para a degradação dos solos nessa parte da bacia como mostram as fotos 1 e 2 .

No que se refere aos cultivos agrícolas, foi por volta do ano de 2000 que começaram a surgir os primeiros cultivos na Bacia Hidrográfica do Ribeirão da Picada/GO, dando início a uma lenta mudança do uso da terra. Atualmente os principais tipos de cultivos agrícolas na bacia são monoculturas de milho, soja e cana. E já é possível observar o quanto o cultivo de monoculturas vem, também, causando a perda de solo por processos erosivos, devido os solos ficarem descobertos nos intervalos entre uma colheita e o próximo plantio. Sendo essas áreas identificadas com grau de fragilidade Forte.

Diante do exposto, os resultados deste trabalho mostraram o quanto é importante a realização de um planejamento ambiental prévio quando 
se trata de atividades econômicas como agricultura e pecuária. É essencial conhecer o ambiente e suas características, principalmente os solos, para que se possam identificar quais culturas são mais adequadas a esse tipo de ambiente como a bacia hidrográfica em questão. A elaboração de um planejamento ambiental da bacia possibilita a escolha do manejo correto dos solos e de outros elementos do ecossistema como a vegetação e os cursos d'água.

\section{Considerações Finais}

Do ponto de vista metodológico, a metodologia para elaboração de fragilidade ambiental proposta por Ross (1994) demonstrou-se muito eficaz no estudo da degradação dos solos da Bacia Hidrográfica do Ribeirão da Picada/GO. A metodologia permitiu verificar as áreas de fragilidade mais forte que coincide com as áreas degradadas, e isso chama atenção para um maior cuidado exatamente com essas áreas. Mas, igualmente mostra a realidade da fragilidade natural do restante da bacia, a montante, que se caso receba o mesmo manejo que a jusante, futuramente poderá se degradar também.

Assim, a realização deste trabalho mostrou o quanto a Bacia Hidrográfica do Ribeirão da Picada/Goiás/Brasil possui um ambiente naturalmente propenso à degradação e como isso vem sendo intensificado pelas ações antrópicas, principalmente atividades de pecuária e agricultura sem manejo correto dos solos.

Contudo, é evidente a necessidade da adoção de políticas ambientais que primem por medidas de mitigação para as áreas à jusante da bacia procurando práticas sustentáveis que evitem a intensificação da degradação dos solos e a ampliação da mesma. Também é importante ressaltar a necessidade da realização de um trabalho social no que se refere a educação ambiental às pessoas que vivem nessa bacia. É preciso conscientizá-las de que em certos locais algumas práticas de agrícolas e pecuárias não são compatíveis às características naturais dessa bacia. Como, por exemplo, uma pastagem degradada não pode ser utilizada por pecuária extensiva sem rotação de pasto. É preciso por um tempo isolar essa área de pastagem para que a vegetação e o solo possam se regenerar. E isso é uma consciência em que alguns agricultores dessa bacia ainda não têm. 
Régia Estevam-Alves, Luzia Francisca-de-Souza, Valéria Maria-de-Souza, Thales Augusto

Ferreira-Queiroz, Jéssica Vieira-Lima. The degradation and fragility of soils in southwestern goias: the watershed case of ribeirao da picada

\section{Referências}

Antunes, E. C. (2006). Recuperação de áreas degradadas por meio de recomposição vegetal em solos arenosos no sudoeste goiano. Tese de doutorado em Ciências Ambientais, Universidade Federal de Goiás. Goiânia, $174 \mathrm{p}$.

Alves, R. E. (2012). Caracterização da paisagem a partir da fragilidade ambiental da Bacia Hidrográfica do Ribeirão da Picada no município de Jataí / GO. Jataí - GO, 2012. Dissertação de mestrado em Geografia, Universidade Federal de Goiás/Campus Jataí, 118 p.

Araújo, R., Goedert, W. J. e Lacerda, M.P.C. (2007). Qualidade de um solo sob diferentes usos e sob Cerrado nativo. Revista Brasileira de Ciência do solo, 31, 1099-1108.

Araujo, G. H. S., Almeida, J. R. e Guerra, A. J. T. (2010). Gestão ambiental de áreas degradadas. Rio de Janeiro: Bertrand Brasil, 320p.

Botelho, R. G. M. (1999). Planejamento ambiental em microbacia hidrografica. In: Guerra, A. J. T.; Silva, A.S.da S.; Botelho, R.G.M. (Orgs). Erosão e conservação dos solos: conceitos, temas e aplicacoes. Rio de Janeiro: Bertrand Brasil, p. 269-299.

Ciampalini, R; Follain, S; Le Bissonnais, Y. (2010). Long-term soil landscape modelling in a Mediterranean agricultural environment. In: World Congress of Soil Science, Soil Solutions for a Changing World. Australia, p. 16-19. Disponível em: http://www.researchgate. net/publication/235943720_Long-term_soil_landscape_modelling in_a_Mediterranean_agricultural_environment

Crepani, E.; Medeiros, J. S.; Azevedo, L. G.; Hernandez Filho, P.; Florenzano, T. G.; Duarte, V. (1996). Curso de Sensoriamento Remoto aplicado ao Zoneamento Ecológico-Econômico. São José dos Campos: INPE. $17 \mathrm{p}$.

Chistofoletti, A. (1999). Modelagem de sistemas ambientais. São Paulo: Edgard Blücher, $256 \mathrm{p}$.

EMBRAPA. (2006) Sistema brasileiro de classificação de solos. (2. ed.). Rio de Janeiro: Empresa Brasileira de Pesquisa/Centro Nacional de Pesquisas de Solos, 306p.

FAO. (2011). The state of the word's land and water resources for food and agriculture (SOLAW) - Managing systems atrisk. Food and Agriculture Organization of the United, Rome and Earthscan, London, 308 p. 
Galindo, I.C.L. ; Ribeiro, M. R. ; Santos, M. F. A. V. ; Lima, J. F. W. F. ; Ferreira, R. ; F. A. L. F. (2008). Relações solo-vegetação em áreas sob processo de desertificação no município de Jataúba/PE. Revista Brasileira de Ciência do Solo, 32,1283-1296.

Gonçalves, A.; Schneider, R. L. (1970). Geologia do Centro-Leste de Mato Grosso. PETROBRÁS, DESUL. Relatório Técnico Interno, ${ }^{\circ} 394$. Ponta Grossa, 43 p.

Gonçalves, G. G. G.; Daniel, O.; Comunello, E.; Vitorino, A. CC. T.; Pereira, H. H. G; Arai, F. K. (2009). Caracterização empírica da fragilidade ambiental em bacias hidrográficas - o caso da bacia do Rio Dourados - MS. In: $2^{\circ}$ Simpósio de Geotecnologias no Pantanal. Anais... Corumbá/MS. Embrapa Informática Agropecuária/INPE, p.422-432.

Guerra, A. J. T.; Silva, A.S.; Botelho, R.G.M. (2010). Erosão e conservação dos solos: conceitos, temas e aplicações. Rio de Janeiro: Bertrand Brasil, 340p.

Guerra, A. J. T.; Jorge, M.C.O. (2012). Geomorfologia do cotidiano: degradação dos solos. Revista Geonorte, Edição Especial, 4(4),116-135.

Hermuche, P. M., Guimarães, G. M. A. e Castro, S. S. (2009). Análise dos compartimentos morfopedológicos como subsídio ao planejamento do uso do solo em Jataí - GO. GEOUSP - Espaço e Tempo, São Paulo, 26, 113-131.

Imeson, A. (2006). Introdução geral à degradação da terra e à desertificação. Projeto Lucinda. Portugal. 15 p. Disponível em: http://geografia.fcsh.unl.pt/lucinda/booklets/A1_Booklet_Final_PT.pdf.

Latrubesse, E. M. (2005). Mapa Geomorfológico do Estado de Goiás: Relatório Final. Goiânia: GOIÁS (Estado) - Secretaria de Indústria e Comércio/Superintendência de Geologia e Mineração. Goiânia, 81 p.

Moragas, W. M. (2005). Análise do sistema ambientais do alto Rio Claro - Sudoeste de Goiás: Contribuição ao planejamento e gestão. Rio Claro-SP, 2005. Tese (Doutorado em Geografia) - Instituto de Geociências e Ciências Exatas da Universidade Estadual Paulista/ Campus de Rio Claro, 226 p.

Projeto Radambrasil. (1982). Programa de Integração Nacional. Levantamento dos recursos naturais, 31, Folha SE. 22, Goiânia: geologia, geomorfologia, pedologia, vegetação e uso potencial da terra. Rio de Janeiro. 
Régia Estevam-Alves, Luzia Francisca-de-Souza, Valéria Maria-de-Souza, Thales Augusto Ferreira-Queiroz, Jéssica Vieira-Lima. The degradation and fragility of soils in southwestern goias: the watershed case of ribeirao da picada

Ross, J. L. S. (1994). Análise empírica da fragilidade dos ambientes naturais e antrópizados. Revista Departamento de Geografia, 8 . FFLCH-USP, São Paulo/SP, p. 63-74.

Ross, J. L. S. (2006). Ecogeorgrafia do Brasil: subsídios para planejamento ambiental. São Paulo: Oficina de Textos, 208 p.

Roxo, M. J. (1993). A acção antrópica no processo de degradação de solos: a Serra de Serpa e Mértola. Tese de doutorado em Geografia, Universidade Nova de Lisboa/Faculdade de Ciências Sociais e Humanas. Lisboa/Portugal, 312p.

Ruiz, J. M. e Bermúdez, F. L. (2009). La erosión del suelo en España. Ed. Sociedad Española de Geomorfología, 441p.

Santos, E. (2005). Mapeamento da fragilidade ambiental da bacia hidrográfica do rio Jirau município de Dois Vizinhos Paraná. Dissertação de Mestrado. (Mestrado em Geografia) - Universidade Federal do Paraná, Curitiba, 123 p.

Silva, I. C. (2008). Mapeamento da Fragilidade Ambiental da Bacia Hidrográfica do Córrego da Onça em Jataí/GO, utilizando técnicas de geoprocessamento. Monografia (Bacharelado em Geografia), Universidade Federal de Goiás/Campus Jataí, 56 p.

Spörl, C. (2007). Metodologia para elaboração de modelos de fragilidade ambiental utilizando redes neurais. Tese de doutorado em Geografia, Faculdade de Filosofia e Ciências Humanas, (FFCH). São Paulo. (185 p.).

Tricart, J. (1977). Ecodinâmica. Rio de Janeiro: Instituto Brasileiro de Geografia e Estatística, 91 p.

Tucci, C. E. M. e Mendes, C. A. (2006). Avaliação ambiental integrada de bacia hidrográfica. Ministério do Meio Ambiente / SQA. - Brasília: MMA, $302 \mathrm{p}$.

UNCCD. (1994). United Nations Conversion to Combat Desertification and Drought. Disponível em: www.unccd.int. 